\title{
Effects of a magnetic cloud simultaneously observed on the equatorial ionosphere in midday and midnight sectors
}

\author{
R. G. Rastogi ${ }^{1}$, H. Chandra ${ }^{1}$, A. C. Das ${ }^{1}$, R. Sridharan ${ }^{2 *}$, B. W. Reinisch ${ }^{3}$, and Khurshid Ahmed ${ }^{4}$ \\ ${ }^{1}$ Physical Research Laboratory, Ahmedabad, India 380009 \\ ${ }^{2}$ Space Physics Laboratory, VSSC, Thiruvananthapuram, India 695022 \\ ${ }^{3}$ University of Massachusetts, Lowell, MA 01854, U.S.A. \\ ${ }^{4}$ Indian Institute of Geomagnetism, New Panvel, Navi Mumbai, India
}

(Received December 28, 2010; Revised October 25, 2011; Accepted October 25, 2011; Online published May 25, 2012)

\begin{abstract}
An impact of a magnetic cloud on the Earth's magnetosphere occurred at 1636 UT on 25 June, 1998, associated with a sudden increase of the solar wind density and velocity, as well as a sudden increase of the zenithal component of the interplanetary magnetic field (IMF- $B_{z}$ ). Following the impact of the magnetic cloud, IMF$B_{z}$ was northward (10 nT) and remained steadily strong (about $15 \mathrm{nT}$ ) for the next six hours. IMF- $B_{z}$ turned southward at 2330 UT on 25 June, 1998, and remained strongly southward ( $-15 \mathrm{nT})$ for the next four hours. During the positive phase of IMF- $B_{z}$, both the Auroral index and ring current index SYM/H remained steadily low indicating complete isolation of the Earth's magnetosphere from the solar wind and no significant changes were observed in the equatorial ionosphere. After the southward turning, the steady southward IMF- $B_{z}$ permitted solar wind energy to penetrate the magnetosphere and caused the generation of a magnetic storm associated with strong auroral electrojet activity $\left(A_{\mathrm{E}}\right.$ index). Strong southward IMF- $B_{z}$ corresponds to the dawn-dusk interplanetary electric field (eastward on the dayside and westward on the night side). The ionograms at Jicamarca (night side) showed strong spread- $F$ and at Thumba (dayside) showed an absence of equatorial type of sporadic- $E$, indicating a dusk-to-dawn electric field. Thus, the observations point to an electric field opposite in direction to that expected by the prompt penetration of the interplanetary electric field. An abnormally-large Auroral index $\left(A_{\mathrm{E}}\right)$ associated with the start of the storm suggests that the cause of the equatorial electric field changes is due to the disturbance dynamo effect.
\end{abstract}

Key words: Interplanetary magnetic field, equatorial ionospheric irregularities.

\section{Introduction}

The equatorial ionosphere is of special interest in studies of solar-terrestrial physics since the discovery by Chapman (1951) of the Equatorial Electrojet (EEJ), a band of eastward-flowing current in the ionospheric $E$-region during the daytime hours. The enhancement of the solar daily range of the horizontal geomagnetic field, $H$, over the magnetic equator was explained by Baker and Martyn (1953) as due to a considerable enhancement of east-west conductivity within a narrow belt over the dip equator $\left( \pm 3^{\circ}\right.$ dip latitude), where the electric and magnetic field are orthogonal to each other. Gouin and Mayaud (1967) observed that the $H$-field at the equatorial station, Addis-Ababa, on some occasions during the daytime, decreased below the night level and suggested this phenomenon to be due to a westward current, which they named the counter electrojet (CEJ).

The ionospheric drift experiment conducted at an equatorial station, Thumba, during 1963-1969, provided unique

\footnotetext{
*Present address: Physical Research Laboratory, Ahmedabad, India 380009 .

Copyright (c) The Society of Geomagnetism and Earth, Planetary and Space Sciences (SGEPSS); The Seismological Society of Japan; The Volcanological Society of Japan; The Geodetic Society of Japan; The Japanese Society for Planetary Sciences; TERRAPUB
}

doi:10.5047/eps.2011.10.010 data to estimate the direction and magnitude of the equatorial electric field. The drifts were westward during daytime and eastward during nighttime (Chandra and Rastogi, 1970). Chandra et al. (1971) showed that the difference between the $\Delta H$ at an equatorial station (Trivandrum) and at a station away from the magnetic equator (Alibag) better represents the electrojet current than the $\Delta H$ at Trivandrum, based on a comparison with the ionospheric drift measurements from Thumba. Denardini et al. (2009) have recently studied features of CEJ events in the Brazilian sector from the difference between $\Delta H$ at Sao Luis (equatorial) and Eusebio (away from the equator), with $\Delta H$ normalized from the mean midnight value of 5 quiet days of the month, and named this the electrojet ground strength.

Using the data from four ionospheric stations within EEJ in Peru during the IGY period, Knecht (1959) identified the special features of the sporadic- $E$ within the EEJ region and denoted this as the q-type of sporadic- $E$ or $E_{\mathrm{s}-\mathrm{q}}$. This layer is transparent to radio waves and permits the recording of echoes from the upper regions of $F$-layers, but can cause scatter echoes over a large range of frequencies, even exceeding $f_{\mathrm{o}} F_{2}$. Rastogi et al. (1971) found that the decrease of $\Delta H$ below the night level (CEJ) and the disappearance of the equatorial $E_{\mathrm{s}-\mathrm{q}}$ are due to the reversal of the daytime electric field to a westward direction, as revealed by the ionospheric drift observations at Thumba. 
The daytime E-W electric field in the $E$-region at low latitudes is communicated to the $F$-region over the magnetic equator via the highly conducting geomagnetic field lines, causing a vertical upward $E \times B$ force on the plasma in the $F$-region. Using the data from an excellent chain of ionospheric stations in India, Rastogi (1959) showed that the vertical plasma drift over the magnetic equator moves the plasma to higher latitudes along the magnetic field, giving rise to a decrease of $f_{\mathrm{o}} F_{2}$ at midday over the magnetic equator and a rise of $f_{\mathrm{o}} F_{2}$ at latitudes around $\pm 15^{\circ}$ dip latitudes. This Equatorial Ionospheric Anomaly (EIA) is intimately related to the equatorial electric field generally indicated by the daily range of the $H$-field. The EIA was found to weaken during the CEJ days.

Another important feature of the equatorial ionosphere is the occurrence of spread echoes in the $F$-region on the ionograms following the rise of the $F$-layer after sunset, known as the Equatorial Spread- $F$ (ESF), and first reported by Booker and Wells (1938). Chandra and Rastogi (1972) were the first to describe the spread- $F$ at equatorial stations to be of the range-spreading type to begin with and to transform itself to a frequency-spreading type at a later stage. It was important that they showed that the ESF develops only after the evening reversal of the electric field. Recently, Hoang et al. (2010) have described the characteristics of spread- $F$ at $\mathrm{Ho}$ Chi Minh city $\left(10.5^{\circ} \mathrm{N}, 106.3^{\circ} \mathrm{E}\right.$, dip lat. $2.9^{\circ} \mathrm{N}$ ) in Vietnam. Though they did not compare their results, the diurnal and seasonal variations of ESF were remarkably similar to that at Thumba and Kodaikanal, described earlier by Chandra and Rastogi (1972).

Rastogi and Woodman (1978) showed that a reversal of the $F$-region horizontal electric field to eastward, at any time of the night, is followed by the generation of the ESF at Huancayo. Rastogi (1983) was first to suggest that the development of spread- $F$ at low latitudes is a consequence of the fountain of plasma irregularities over the dip equator caused by the eastward electric field, very similar to the phenomenon of EIA. Rastogi (1980a, b) suggested that the seeding of the ESF irregularities is due to the gradient drift instability mechanism at the base of the $F$-layer and may develop later throughout the $F$-layer by a Rayleigh-Taylor instability mechanism. There have been several studies on ESF (Woodman and LaHoz, 1976; Fejer and Kelley, 1980; Abdu et al., 1981; Aarons, 1982).

The ionospheric drift observations at Thumba showed for the first time the effect of IMF on EEJ (Rastogi and Chandra, 1974). An increasing zenithal component of IMF was shown to be associated with an increasing anti- $S_{\mathrm{q}}$ electric field during the day-time as well as the night-time hours, based on hourly data for the three hours around local midday and three hours around local midnight for a large number of days during the year 1967. This was interpreted as due to the decrease of the equatorial dawn-to-dusk electrostatic field with an increasing southward component of IMF.

Fejer et al. (1979) examined the effect of IMF on the vertical $F$-region drifts over Jicamarca and found the mean hourly drift between 1000 and 1400 LT to be $15.8 \pm 7.7 \mathrm{~m} / \mathrm{s}$ for positive, and $18.3 \pm 7.3 \mathrm{~m} / \mathrm{s}$ for negative, values of IMF$B_{z}$. Thus, the north-south component of IMF was found to have some effect: the large standard deviation in their analysis seems to be due to the large interval of daytime for which the drift data were averaged. They further examined the mean drifts for individual groups of IMF- $B_{z}$ values and concluded that the drifts were essentially independent of $B_{z}$. The data set was not sufficiently large to detect small modifications due to IMF- $B_{z}$.

The solar wind interaction with the magnetosphere is quite a complex process and largely depends on the IMF conditions. Prompt penetration electric field is generally composed of convection electric field and over shielding electric field. The shielding electric fields are built up toward the equator of the auroral latitudes and are often reversed when the convection field is decreased suddenly, because of the northward turning of the IMF- $B_{z}$, and known as over shielding electric field. For IMF- $B_{z}$ turning northward (over shielding effect) the interplanetary electric field is directed westward during day and eastward during night, while for southward turning of IMF- $B_{z}$ (under shielding effect) the resulting field is directed eastward during day and westward during night. Thus the prompt penetration electric field enhances the daytime eastward dynamo field.

Another important mode of coupling of the low-latitude ionosphere with the solar wind is the precipitation of solar plasma along the open geomagnetic field lines connected to the IMF lines. First, the energetic particles create ionization in the auroral $E$-region and generate strong auroral electrojet currents which may be completed through the dayside equatorial region that has a large electric conductivity. The second process is through the disturbance dynamo electric field driven by storm time neutral winds. The global neutral wind system responds to the high-latitude energy and momentum input with the ionosphere-thermosphere from the magnetosphere. This is a delayed effect and develops over a period of hours, and can persist for many hours due to the inertia of the neutral atmosphere.

Rastogi and Patel (1975) noted that large and quick changes in the direction of IMF from a southward to a northward direction are associated with the imposition of an interplanetary electric field directed from the dusk-to-dawn direction (eastward in the night sector and westward in the day side sector). They showed that an onset of northward turning of IMF- $B_{z}$ at 0840 UT on 3 July, 1968, was accompanied with the sudden reversal of VHF backscatter radar drifts in the $E$ - and $F$-regions over Jicamarca and a positive pulse in the geomagnetic $H$-field at Huancayo. About an hour later, strong equatorial spread- $F$ irregularities were recorded on ionograms over Huancayo (Rastogi, 1977).

Thus, it is amply shown that the reversals of IMF- $B_{z}$ can generate fresh ESF irregularities in the night sector, and can cause the sudden disappearance of $E_{\mathrm{s}-\mathrm{q}}$ irregularities in the day sector, of the hemisphere. There have been a number of case studies describing the storm time effects in the equatorial ionosphere, but restricted to a particular longitude region. Sastri et al. (2002) reported the response of the equatorial $F$-region in the Indian midnight sector to the magnetic storm of July 15, 2002. Maruyama (2006) reported an enhancement in TEC during the November, 2004, magnetic storm event. Abdu et al. (2003) described the magnetospheric disturbance (prompt penetration of the eastward electric field) induced equatorial plasma-bubble develop- 


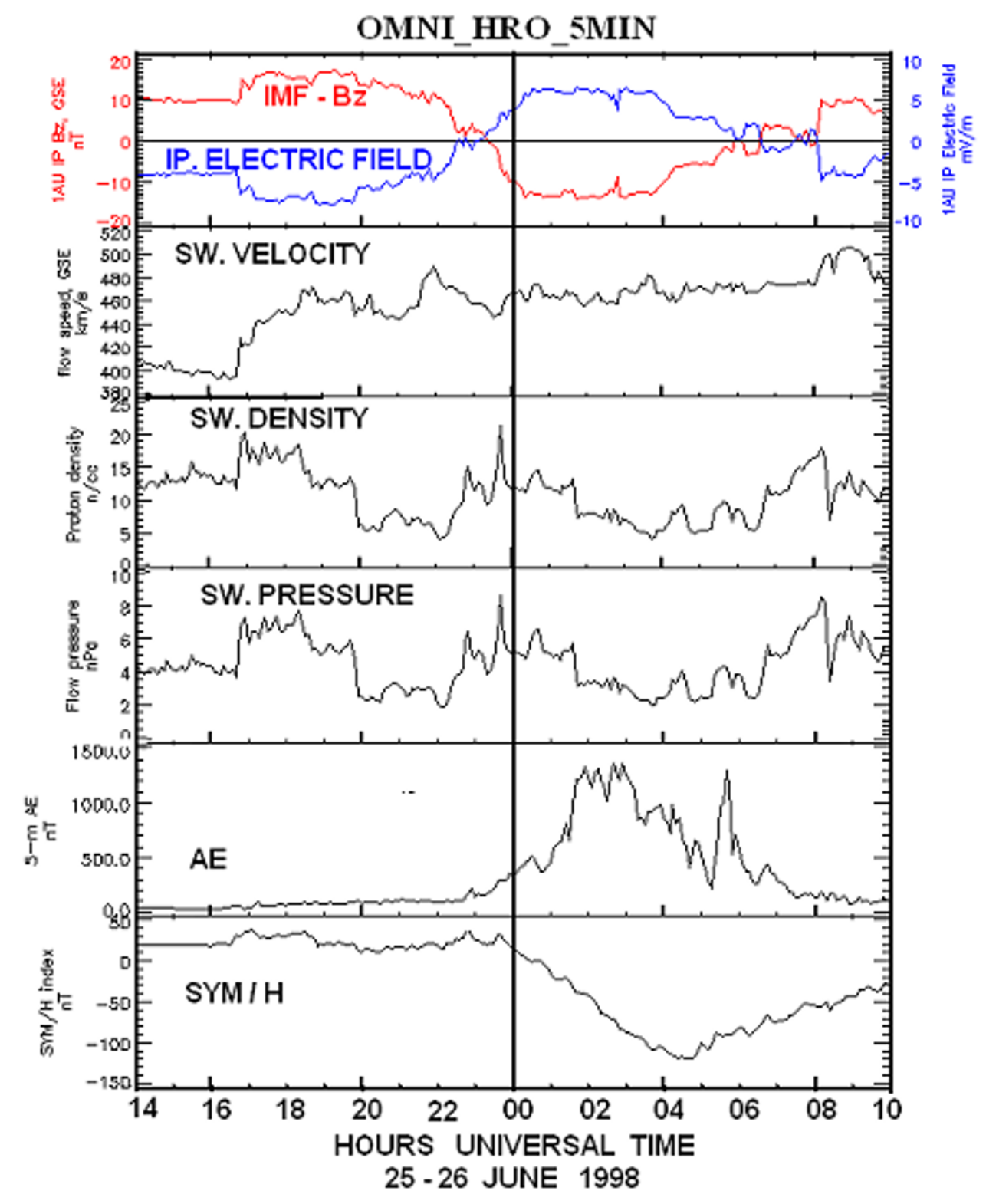

Fig. 1. The temporal variations of solar wind velocity, ion density, pressure, interplanetary magnetic field, Auroral current index and Sym/H index during the magnetic storm following the SC at 1636 UT on 25 June, 1998.

ment. Basu et al. (2001) studied ionospheric effects of major magnetic storms during September-October, 1999, based on GPS, VHF/UHF scintillations and in-situ density measurements and reported strong irregularities associated with the prompt penetration electric fields in the evening hours.

There are not many studies of the response of the equatorial and low-latitude ionosphere-thermosphere at different longitude sectors to geomagnetic storms. Abdu et al. (2007) studied the ionospheric $F$-layer responses at equatorial, low, and middle, latitudes to the geomagnetic storm of October, 2003, based on ionosonde/GPS data in the Brazilian and Japanese longitude sectors. Tulasi Ram et al. (2008) studied the response of post sunset equatorial spread- $F$ during five geomagnetic storms based on data in the Indian, and Japanese sectors, and Kwajalein (covering about $90^{\circ}$ longitude), and showed the development of plasma bubbles due to the prompt penetration of the eastward elec- tric field in the dusk sector. Bagia et al. (2011) have very recently reported the response of the equatorial and lowlatitude ionosphere-thermosphere to the geomagnetic storm of 15 May, 2005, from observations in the Indian longitude sector $\left(70^{\circ}-78^{\circ} \mathrm{E}\right)$, and the American longitude sector $\left(270-288^{\circ} \mathrm{E}\right)$, based on GPS observations. However, case studies of the simultaneous effects on ESF (nightside) and $E_{\text {s-q }}$ (dayside) related to any parameters of solar wind or magnetic field have not been reported so far.

\section{Observations}

A solar wind discontinuity arrived at the Earth's magnetosphere, causing a sudden commencement, at 1636 UT on 25 June, 1998, followed by a strong magnetic storm with a minimum $D_{\text {st }}$ of less than $-100 \mathrm{nT}$. This was a clear example of a CME, as described by Russell (1999). This has been listed as a major storm (complex non MC/kinky HCS/ICME i.e. a magnetic cloud) during the solar cycle 23 
(a)

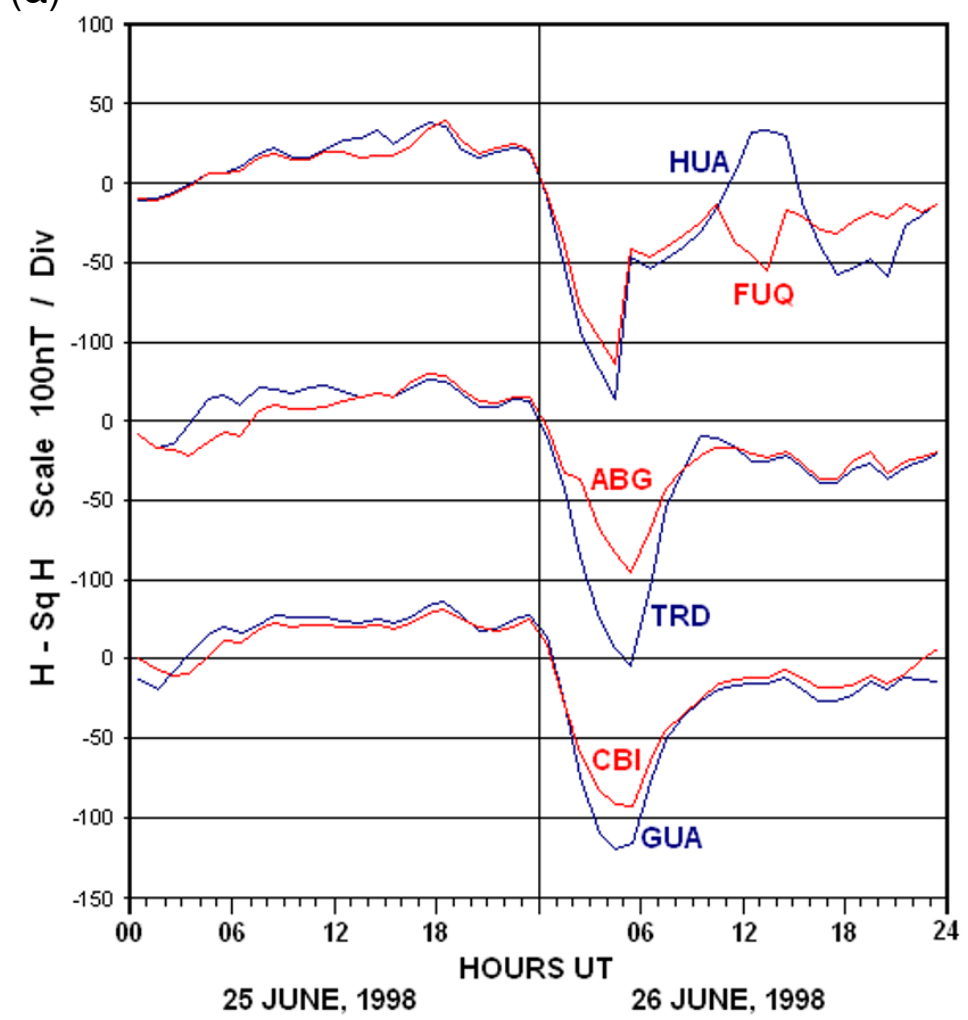

(b)

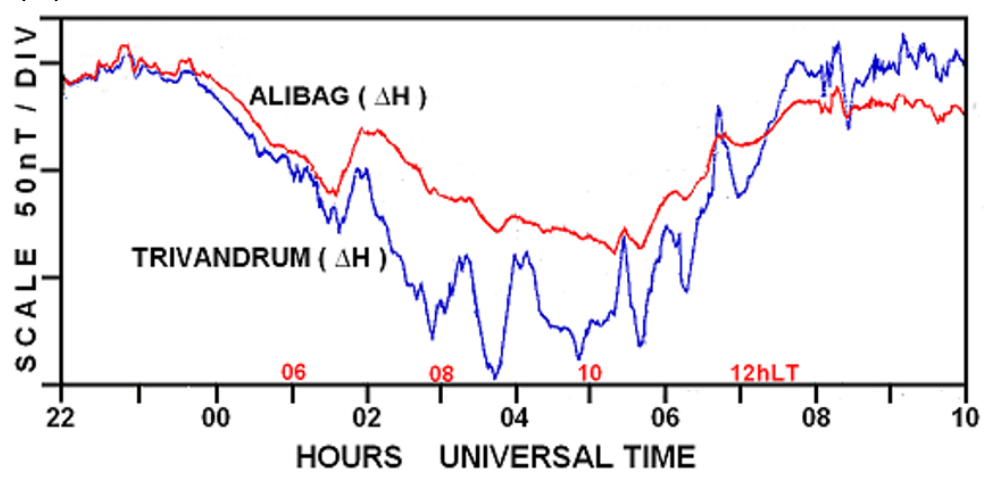

25-26 JUNE, 1998

(c)

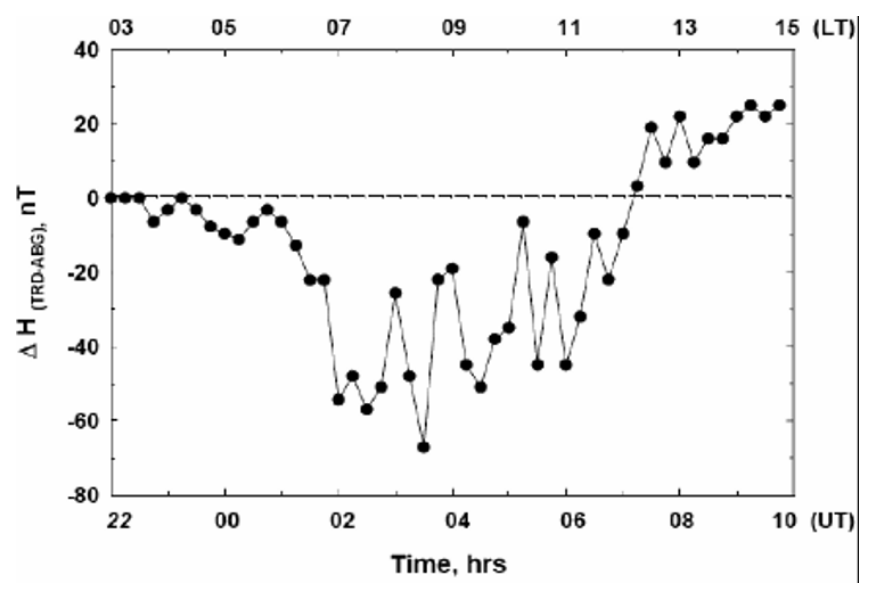

Fig. 2. (a) Variations of the $H$-field minus the quiet day $H$-field $\left(S_{\mathrm{q}} H\right)$ at pairs of equatorial and low-latitude stations in Indian (Trivandrum, Alibag), Pacific (Guam, Chichijima) and Peruvian (Huancayo, Fuquene) longitudes on 25 and 26 June, 1998 (UT). (b) The variations of $\Delta H$ at Trivandrum and Alibag superimposed at midnight for the period 22 UT on 25 June, 1998, to 10 UT on 26 June, 1998. (c) The difference of $\Delta H$ at Trivandrum and Alibag from 22 UT on 25 June, 1998, to 10 UT on 26 June, 1998, (03 h to $15 \mathrm{~h}$ local time) from quarter-hourly values. 


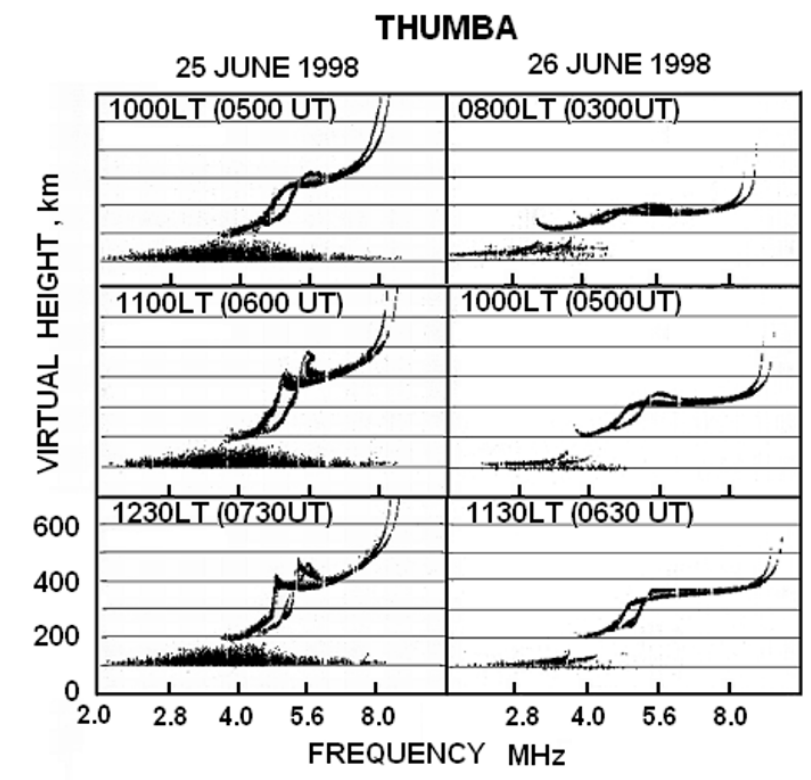

(a)

(b)

Fig. 3. Selected ionograms at Thumba (close to Trivandrum) on 25 and 26 June, 1998.

by Echer et al. (2008). Fortunately, besides the complete set of solar wind data, the ionospheric and geomagnetic data were also available at equatorial stations in the Indian (daytime) and American (nighttime) sectors. Geomagnetic data used are from Trivandrum $\left(8.5^{\circ} \mathrm{N}, 77.0^{\circ} \mathrm{E}\right.$, dip $\left.1.0^{\circ} \mathrm{N}\right)$, and Alibag $\left(18.6^{\circ} \mathrm{N}, 73.0^{\circ} \mathrm{E}\right.$, dip $\left.25.7^{\circ} \mathrm{N}\right)$, in India. Ionograms from Thumba (close to Trivandrum) and Huancayo $\left(12^{\circ} \mathrm{S}\right.$, $75^{\circ} \mathrm{W}$, dip $1^{\circ} \mathrm{N}$ ) are used. Solar wind, IMF, $A_{\mathrm{E}}$ and SYM/H, data are obtained from NASA CDAWEB.

In Fig. 1 are re-plotted the solar wind 5-minute average data, IMF- $B_{z}$ and interplanetary electric field data, Auroral $A_{\mathrm{E}}$ index and SYM/H data. The solar plasma intercepted the Earth's magnetosphere causing an SC at 1636 UT on 25 June, 1998. Solar wind density, $n$, was around $13 \mathrm{~cm}^{-3}$ between 14-16 UT and increased suddenly at 1636 UT to about $20 \mathrm{~cm}^{-3}$ and remained at that level up to 1800 UT. Solar wind velocity, $V$, also increased from about 380 $\mathrm{km} / \mathrm{s}$ to $430 \mathrm{~km} / \mathrm{s}$ at $1636 \mathrm{UT}$ and continued to increase to $460 \mathrm{~km} / \mathrm{s}$ at $1900 \mathrm{UT}$. This caused an increase of solar wind pressure $\left(n V^{2}\right)$ from $4 \mathrm{hPa}$ to $7 \mathrm{hPa}$ at the time of SC. The IMF- $B_{z}$ had an increase from $+10 \mathrm{nT}$ to $+15 \mathrm{nT}$ at $\mathrm{SC}$, which, coupled with solar wind velocity, caused a decrease of interplanetary electric field $\left(E_{y}=-V_{x} \times B_{z}\right)$ from -9 $\mathrm{mV} / \mathrm{m}$ to $-14 \mathrm{mV} / \mathrm{m}$. These changes in the solar wind parameter had caused a SC of $50 \mathrm{nT}$ at Huancayo (1136 LT) and of $45 \mathrm{nT}$ at Trivandrum (2144 LT).

IMF- $B_{z}$ was strongly northward (10 nT) before the impact of the cloud on the magnetosphere and remained northward stronger than $10 \mathrm{nT}$ until $2300 \mathrm{UT}$, after which it gradually turned southward reaching a value of $-12 \mathrm{nT}$ at 0000 UT on 26 June, 1998, and remained steady at that level until 0400 UT. There being no large changes in solar wind velocity, the resultant electric field $E_{y}=-V_{x} \times B_{z}$ was almost a mirror image of $B_{z}$, being negative before UT midnight and positive thereafter. It is to be noted that there were no large short time fluctuations in IMF $B_{z}$ during this period. The SYM/H index was constant around $+20 \mathrm{nT}$ up to $00 \mathrm{UT}$, after which it started decreasing to a minimum value of $-120 \mathrm{nT}$ around $0430 \mathrm{UT}$. The auroral electrojet (indicated by the $A_{\mathrm{E}}$ index) showed a first increase at 2347 UT and maximum substorm activity during 02-04 UT with a peak of $1400 \mathrm{nT}$ at $0255 \mathrm{UT}$. The absence of any equatorial, or Auroral, activities due to a large northward IMF indicate the isolation of the Earth's magnetosphere from the solar wind.

In Fig. 2(a) are shown the variations of the $H$-field minus the quiet day $H$-field $\left(S_{\mathrm{q}} H\right)$ at pairs of equatorial and lowlatitude stations at Indian, Pacific and Peruvian longitudes for 25 June and 26 June, 1998 (UT). The stations chosen are Trivandrum (TRD, $\left.8.5^{\circ} \mathrm{N}, 77.0^{\circ} \mathrm{E}\right)$ and Alibag (ABG, $18.6^{\circ} \mathrm{N}, 72.9^{\circ} \mathrm{E}$ ) in the Indian sector; Huancayo (HUA, $-12.0^{\circ} \mathrm{N}, 284.7^{\circ} \mathrm{E}$ ) and Fuquene (FUQ, $5.5^{\circ} \mathrm{N}, 286.3^{\circ} \mathrm{E}$ ) in the American sector; and Guam (GUA, $13.6^{\circ} \mathrm{N}, 144.9^{\circ} \mathrm{E}$ ) and Chichijima (CBI, $\left.27.1^{\circ} \mathrm{N}, 142.2^{\circ} \mathrm{E}\right)$ in the Pacific sector. It is seen that the storm time variation was evident most at the Indian longitude (noon sector) where the decrease of $\left(H-S_{\mathrm{q}} H\right)$ at the equatorial station Trivandrum (TRD) was more than $100 \mathrm{nT}$ with respect to that at the non-equatorial station Alibag (ABG). Along the Pacific longitude in the local afternoon hours, the effect was reduced. It is interesting to note that even at the Peruvian longitude, which was in the midnight sector, the decrease of $\left(H-S_{\mathrm{q}} H\right)$ was significantly larger at Huancayo than at Fuquene. Thus, there was a persistent westward current over the equatorial latitudes superimposed over the ring current. The presence of such a current and its longitudinal/local-time effects needs to be understood and explained.

In Fig. 2(b) are shown the temporal variations of $\Delta H$ (with respect to $00 \mathrm{hr} \mathrm{LT}$ ) at Trivandrum, an equatorial station, and at Alibag, a low-latitude station outside EEJ, from 22 UT on 25 June, 1998, to 10 UT on 26 June 1998. The local time is also marked in the figure. The two curves are 


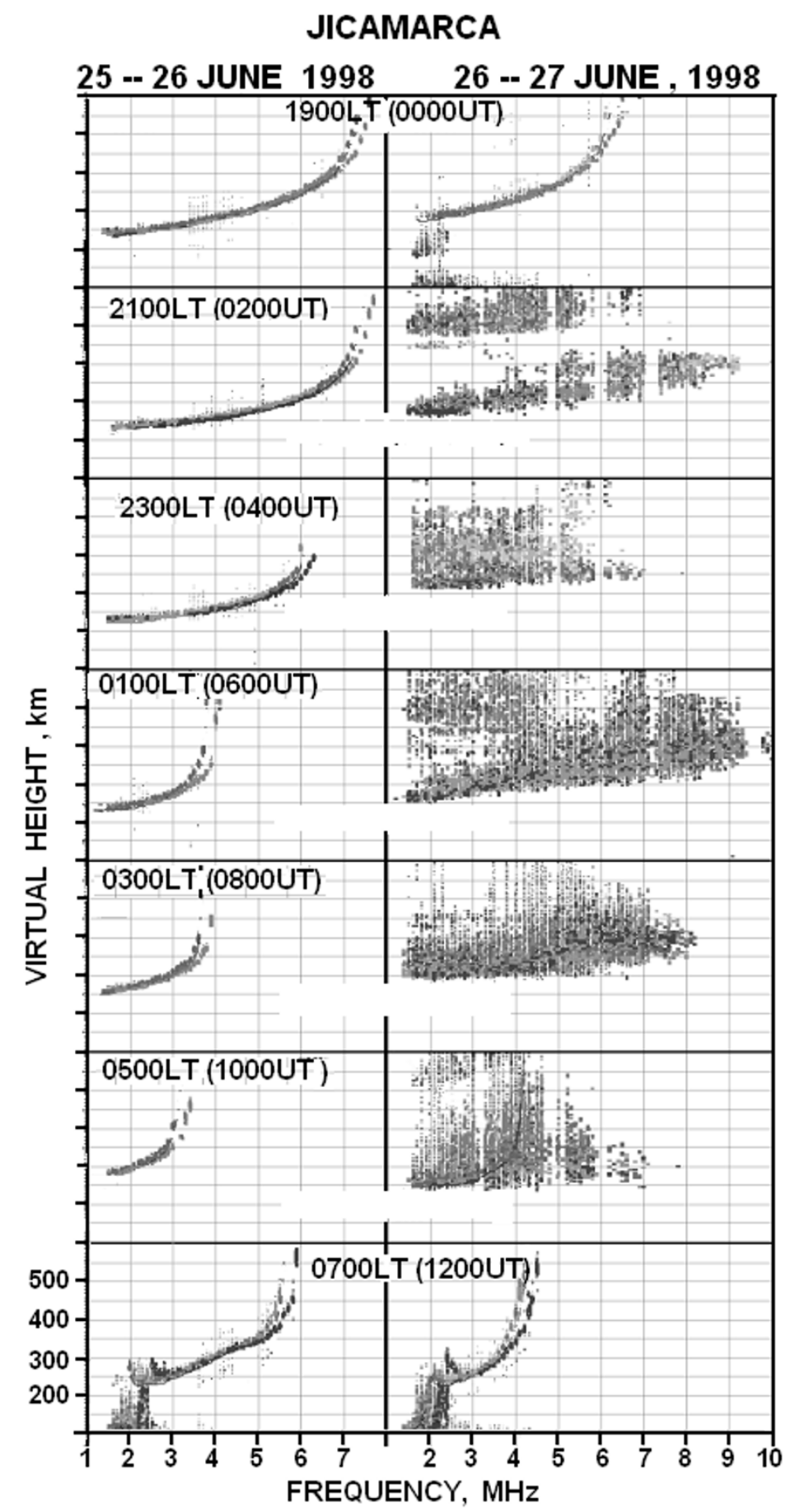

Fig. 4. Selected ionograms at Jicamarca on 25 and 26 June, 1998.

superimposed at midnight so that one can see easily the difference between $\Delta H$ at the two stations. From 0500 to $1200 \mathrm{~h}$ local time the values of $\Delta H$ at Trivandrum are lower than the corresponding $\Delta H$ values at Alibag and significantly lower from 0630 to $1130 \mathrm{~h}$ local time. Thus $\Delta H$ (TRD-ABG) being negative indicates a counter electrojet condition in the Indian sector during the complete forenoon hours. The difference of $\Delta H$ at Trivandrum and Alibag is also plotted in Fig. 2(c) from 22 UT to 10 UT (03 to $15 \mathrm{~h}$ local time) based on quarter hourly values. The negative values from $0100 \mathrm{UT}$ to $07 \mathrm{UT}$ ( $06 \mathrm{~h}$ to $12 \mathrm{~h}$ local time) indicate a counter electrojet with a maximum value of $-67 \mathrm{nT}$ at $3.5 \mathrm{UT}$ ( $8.5 \mathrm{~h}$ local time).

Rastogi et al. (1971) showed that, during daytime, no$E_{\mathrm{s}-\mathrm{q}}$ condition at Kodaikanal, the $E$-region ionospheric drifts at Thumba were eastward in contrast to a westward drift during normal periods. Using modified range-timeintensity records of VHF backscatter echoes at Jicamarca, Rastogi et al. (1977) showed that the $E$-region echoes disappeared precisely at the time when $\Delta H$ at an equatorial station minus the $\Delta H$ at a non-equatorial station turns negative, irrespective of the absolute value of $\Delta H$ at the equator. Thus, the occurrence of the counter electrojet ( $\Delta H_{\text {equatorial }}-\Delta H_{\text {non-equatorial }}$ becoming negative) is asso- 
ciated with the disappearance of $E_{\mathrm{s}-\mathrm{q}}$ at Thumba or the reversal of the ionospheric electric field to the westward direction, sometimes due to the reversal of IMF- $B_{z}$.

In Fig. 3 are shown a set of ionograms at Thumba, near Trivandrum, during the daytime on a normal quiet day, 25 June, 1998, and on a storm day 26 June, 1998. On 25 June, 1998 (Fig. 3(a)), strong $E_{\mathrm{s}-\mathrm{q}}$ echoes showing a strong characteristic triangular configuration of diffuse echoes at low frequencies, and scatter echoes for extended frequencies, indicate the presence of strong $E \times B$ gradient drift irregularities in the $E$-region during these times. The $F_{2}$ traces indicate the upward lifting of the $F$-region, characteristic of the EIA due to a strong eastward electric field at these times. These conform to a normal $E$ - and $F$-region at the EEJ on quiet days.

Figure 3(b) shows ionograms at Thumba on the storm day 26 June, 1998. Each of the ionograms show a complete absence of $E_{\mathrm{s}}$ scatter echoes and the normal $E$-layer echoes were clearly recorded. The $F$-layers traces also indicate absence of the uplifting of the $F$-region indicating the weakening, or absence, of the EIA during the forenoon hours. These features are consistent with a westward ionospheric electric field in the dayside of the Earth due to the positive interplanetary electric field.

In Fig. 4 (left panel) are reproduced the digital ionograms at the American sector equatorial station Jicamarca at alternate hours from 00 UT to 12 UT of 25 June 1998. Referring to Fig. 4 the height of the base of the $F$ layer, $h^{\prime} F$ was 230 $\mathrm{km}$ at $00 \mathrm{UT}$ (19 LT) and remained so during the whole night. This absence of the height rise and, consequently, the absence of any vertical gradient of the plasma density caused the inhibition of the spread- $F$ irregularities. It may be mentioned that during the June solstices (winter) the $S_{\mathrm{q}}$ electric field reversed before the ionospheric sunset and inhibits the height rise of the $F$-layer (Rastogi, 1980b).

In Fig. 4 (right panel) are reproduced the ionograms at Jicamarca on 26 June, 1998, for 00 UT to $12 \mathrm{~h}$ UT. The ionograms at 00 UT (19 LT) and before did not show any spread$F$ echoes on the $F$-trace. At 02 UT (21 LT) strong spread- $F$ echoes were recorded throughout the whole trace. In subsequent ionograms, the spread echoes got stronger and were inhibited with the rising of the sun in the ionosphere. It is important to note that there was no height rise of the base of the $F$-region before the inhibition of the spread- $F$.

These features are consistent with the presence of a westward electric field in the nightside of the Earth due to the positive interplanetary electric field.

\section{Discussion}

Rastogi and Patel (1975) have suggested that large and quick changes in the direction of the IMF from southward to northward is associated with the penetration of the interplanetary electric field to the equatorial ionosphere due to an over shielding effect. Somehow, this has been later generalized as the phenomenon of northward turning of the IMF- $B_{z}$, irrespective of the pre-disturbance value. Patel (1978) reexamined the relationship between the disappearance of $E_{\mathrm{s}-\mathrm{q}}$ at Huancayo, the electrojet index, and the IMF$B_{z}$, and showed some events of the disappearance of $E_{\mathrm{s}-\mathrm{q}}$ without a significant change of IMF- $B_{z}$. Rastogi (1981) showed that the disappearance of $E_{\mathrm{s}-\mathrm{q}}$ is complex, and is affected by the equatorial electric field due to atmospheric tides, the extension of the polar electrojet current to low latitudes, and due to changes in IMF- $B_{z}$. He showed that the relative importance of these sources can be easily estimated by examining the magnetograms of neighbouring electrojet stations.

The present paper describes an event when IMF- $B_{z}$ increased from an initial positive value of $10 \mathrm{nT}$ to $15 \mathrm{nT}$ during the impact of a solar plasma cloud with the Earth's magnetosphere. The feature of this event was that the interplanetary electric field was strongly positive during the period of the magnetic storm. The disappearance of $E_{\mathrm{s}-\mathrm{q}}$ on the dayside is opposite to the effect due to direct penetration of the electric field to the equatorial region (under shielding effect). It actually suggests an interesting (evidence) situation of penetration of electric field due to an over shielding effect. However, if one examines the interplanetary magnetic field, it does not show any sudden reversal of IMF from a southward to a northward direction, which is a signature for an over shielding effect and, as a result, this possibility has to be abandoned. This then requires an alternative process that may support the observations. It may be noted that there was a simultaneous surge of the $A_{\mathrm{E}}$ index with the start of the magnetic storm, indicated by the large SYM/H index. The observed dayside westward electric field at Thumba seems to be due to the disturbance dynamo, caused by the Joule heating of the auroral ionosphere, that gives rise to electric fields opposite to the dynamo fields at low latitudes with a delay of a few hours. In the present case, the build up of the $A_{\mathrm{E}}$ index started around $2300 \mathrm{UT}$ and the disappearance of $E_{\mathrm{s}-\mathrm{q}}$ was seen around 0300 UT. It supports the above mechanism and is, we believe, an important scientific contribution towards the understanding of the physical processes at the equatorial ionosphere as a result of the disturbance dynamo during a geomagnetic storm. In addition, there are wave-like fluctuations in the $\Delta H$ at Trivandrum with a period of about an hour. These are likely to be due to large-scale gravity waves generated at the auroral latitudes. Sastri et al. (2000) had earlier reported the ionospheric response to the magnetic storm of November, 1993, at the Indian longitudes that showed the effects due to electric fields of both prompt penetration and disturbance dynamo origin, and also due to large-scale gravity waves originated from auroral latitudes.

\section{Conclusion}

The equatorial ionosphere at American and Indian longitudes was greatly affected by the impact of a magnetic cloud on the Earth's magnetosphere at 1636 UT on 25-26 June, 1998, associated with a sudden increase in solar wind density, velocity and sudden changes in IMF.

During the phase of a positive IMF- $B_{z}$, there were no significant changes, indicating a complete isolation of the Earth's magnetosphere from the solar wind.

During the phase of a southward IMF- $B_{z}$ there was a disappearance of $E_{\mathrm{s}-\mathrm{q}}$ at Thumba in the dayside and a strong spread- $F$ at Huancayo in the nightside indicating a dusk-todawn electric field, which is opposite to the prompt penetration electric field (under a shielding effect). 
An abnormally-large Auroral index $\left(A_{\mathrm{E}}\right)$ associated with the storm suggests the cause of the equatorial electric field changes to be due to the disturbance dynamo effect.

Acknowledgments. Thanks are due to the Physical Research Laboratory, Ahmedabad, and the Indian Space Research Organization for the facilities for the analysis of data sets recorded by various research centers. The interplanetary data were obtained from http://cdaweb.gsfc.nasa.gov and the digisonde ionograms from http://ulcar.uml.edu/DiDbase.

\section{References}

Aarons, J., Global morphology of ionospheric scintillations, Proc. IEEE, 70, 360-378, 1982.

Abdu, M. A., J. A. Bittencourt, and I. S. Batista, Magnetic declination control of the equatorial $F$ region dynamo electric field development and spread-F, J. Geophys. Res., 86, 11443-11446, 1981.

Abdu, M. A., I. S. Batista, H. Takahashi, J. MacDougall, J. H. Sobral, A. F. Medeiros, and N. B. Trivedi, Magnetospheric disturbance induced equatorial plasma bubble development and dynamics, J. Geophys. Res., 108, 1449, doi:10.1029/2002JA009721, 2003.

Abdu, M. A., T. Maruyama, I. S. Batista, S. Saito, and M. Nakamura, Ionospheric responses to the October 2003 superstorm: Longitude/local time effects over equatorial, low and middle latitudes, J. Geophys. Res., 112, A10306, doi:10.1029/2006JA012228, 2007.

Bagia, M. S., K. N. Iyer, H. P. Joshi, S. V. Thampi, T. Tsugawa, S. Ravindran, R. Sridharan, and B. M. Pathan, Low-latitude ionospherethermosphere response to storm time electrodynamical coupling between high and low latitudes, J. Geophys. Res., 116, A01303, doi:10.1029/2010JA015845, 2011.

Baker, W. G. and D. F. Martyn, The electric current in the ionosphere, Part 1, The conductivity, Phil. Trans. R. Soc. Lond., A246, 281-294, 1953.

Basu, Su., S. Basu, C. E. Valladares, H. C. Yeh, S. Y. Su, E. MacKenzie, P. J. Sultan, J. Aarons, F. J. Rich, P. Doherty, K. M. Groves, and T. W. Bullett, Ionospheric effects of major magnetic storms during the interplanetary space weather period of September and October 1999: GPS observations, VHF/UHF scintillations, and in situ density structures at middle and equatorial latitudes, J. Geophys. Res., 106, 30389-30413, 2001.

Booker, H. G. and H. W. Wells, Scattering of radio waves by the F-region of the ionosphere, J. Geophys. Res., 43, 249-256, 1938.

Chandra, H. and R. G. Rastogi, Daily variation of F-region drifts at Thumba, J. Atmos. Terr. Phys., 32, 1309-1311, 1970.

Chandra, H. and R. G. Rastogi, Spread-F at magnetic equatorial station Thumba, Ann. Geophys., 28, 37-44, 1972.

Chandra, H., R. K. Misra, and R. G. Rastogi, Equatorial ionospheric drift and the electrojet, Planet. Space. Sci., 9, 1497-1503, 1971.

Chapman, S., The equatorial electrojet as detected from the abnormal electric current distribution above Huancayo and elsewhere, Arch. Meteorol. Gepphysik. Bioklimatol., A4, 368-392, 1951.

Denardini, C. M., M. A. Abdu, H. C. Aveiro, L. C. A. Resende, P. P. S. C. Almeida, E. P. A. Olivio, J. H. A. Sobral, and C. M. Wrasse, Counter electrojet features in the Brazilian sector: Simultaneous observations by radar, digital ionosonde and magnetometers, Ann. Geophys., 27, 15931603, 2009.

Echer, E., W. D. Gonzalez, B. T. Tsurutani, and A. C. L. Gonzalez, Interplanetary condition causing intense geomagnetic storms (Dst $\leq-100$ nT) during solar cycle 23 (1996-2006), J. Geophys. Res., 113, A05221, doi:10.1029/2007JA012744, 2008.

Fejer, B. G. and M. C. Kelley, Ionospheric irregularities, Rev. Geophys., 18, 401-450, 1980.
Fejer, B. G., C. A. Gonzales, D. T. Farley, and M. C. Kelley, Equatorial electric field during magnetically disturbed condition 1 . The effects of the interplanetary magnetic field, J. Geophys. Res., 84(A10), 5797$5802,1979$.

Gouin, P. and P. N. Mayaud, A propos de l'existence possible d'un contre electrojet aux latitudes magnetiques equatorials, Ann. Geophys., 23, 4147, 1967.

Hoang, T. L., M. A. Abdu, J. MacDougall, and I. S. Batista, Longitudinal differences in the equatorial spread-F characteristics between Vietnam and Brazil, Adv. Space Res., 45, 351-360, 2010.

Knecht, R. W., An additional lunar influence on equatorial Es at Huancayo, J. Atmos. Terr. Phys., 14, 348-349, 1959.

Maruyama, T., Extreme enhancement in total electron content after sunset on 8 November 2004 and its connection with storm enhanced density, Geophys. Res. Lett., 33, L20111, doi:10.1029/2006GL027367, 2006.

Patel, V. L., Interplanetary magnetic field variations and the electromagnetic state of the equatorial ionosphere, J. Geophys. Res., 83, 21372144, 1978.

Rastogi, R. G., The diurnal development of the anomalous equatorial belt in the F2 region of the ionosphere, J. Geophys. Res., 64, 727-732, 1959.

Rastogi, R. G., Equatorial Spread F and interplanetary magnetic field, $J$. Geomag. Geoelecr., 29, 557-561, 1977.

Rastogi, R. G., Seasonal and solar cycle variations of equatorial spread-F in the American zone, J. Atmos. Terr. Phys., 42, 593-597, 1980a.

Rastogi, R. G., Seasonal variation of equatorial spread-F in the American and Indian zones, J. Geophys. Res., 85, 722-726, 1980 b.

Rastogi, R. G., Equatorial counter electrojet and interplanetary magnetic field, Ind. J. Radio Space Phys., 10, 1-15, 1981.

Rastogi, R. G., Tropical Spread-F, Ind. J. Radio Space Phys., 12, 104-113, 1983.

Rastogi, R. G. and H. Chandra, Interplanetary magnetic field and the equatorial ionosphere, J. Atmos. Terr. Phys., 32, 377-379, 1974.

Rastogi, R. G. and V. L. Patel, Effect of interplanetary magnetic field on the ionosphere over the magnetic equator, Proc. Ind. Acad. Sci., A82, 121-141, 1975.

Rastogi, R. G. and R. F. Woodman, Spread F in equatorial ionograms associated with reversal of horizontal F-region electric field, Ann. Geophys., 34, 31-36, 1978.

Rastogi, R. G., H. Chandra, and S. C. Chakravarty, The disappearance of equatorial Es and the reversal of electric current, Proc. Ind. Acad. Sci., 74A(2), 62-67, 1971.

Rastogi, R. G., B. G. Fejer, and R. F. Woodman, Sudden disappearance of VHF radar echoes from the equatorial E-region irregularities, Ind. J. Radio Space Phys., 6, 39-43, 1977.

Russel, C. T., Magnetic stress in solar system plasmas, Aust. J. Phys., 52, 733-751, 1999.

Sastri, J. H., N. Jyothi, V. V. Somayajulu, H. Chandra, and C. V. Devasia, Ionospheric storm of early November 1993 in the Indian equatorial region, J. Geophys. Res., 105, 18443-18455, 2000.

Sastri, J. H., K. Niranjan, and K. S. V. Subbarao, Response of the equatorial ionosphere in the Indian (midnight) sector to the severe magnetic storm of July 15, 2000, Geophys. Res. Lett., 29, doi:10.1029/2002GL015133, 2002.

Tulasi Ram, S., P. V. S. Rama Rao, D. S. V. V. D. Prasad, K. Niranjan, S. Gopi Krishna, R. Sridharan, and S. Ravindran, Local time dependent response of postsunset ESF during geomagnetic storms, J. Geophys. Res., 113, A07310, doi:10.1029/2007JA012922, 2008.

Woodman, R. F. and C. LaHoz, Radar observations of F-region equatorial irregularities, J. Geophys. Res., 81, 5447-5466, 1976.

R. G. Rastogi, H. Chandra (e-mail: hchandra44@gmail.com), A. C. Das, R. Sridharan, B. W. Reinisch, and Khurshid Ahmed 